\title{
Bilingual education as a prospective form of tertiary education in higher education institutions
}

Poddubnaya Yana Nikolaevna ${ }^{1}$ Kotov Konstantin Sergeevich ${ }^{2}$

Slukina Anastasia Alekseevna ${ }^{3}$ Aleksandrova Larisa Gennadevna ${ }^{4}$ Martynova Anastasia Sergeevna ${ }^{5}$

\author{
Journal for Educators, Teachers and Trainers, Vol. 12 (1)
}

https://jett.labosfor.com/

Date of reception: 19 September 2020

Date of revision: 11 Dec 2020

Date of acceptance: 12 March 2021

Poddubnaya Yana Nikolaevna, Kotov Konstantin Sergeevich, Slukina Anastasia Alekseevna, Aleksandrova Larisa Gennadevna, Martynova Anastasia Sergeevna (2021). Bilingual education as a prospective form of tertiary education in higher education institutions. Journal for Educators, Teachers and Trainers, Vol. 12(1). 15 - 21.

${ }^{1,2,3,4}$ School of Education, Far Eastern Federal University, (branch) in Ussuriysk, Russia

${ }^{5}$ Federal State Budgetary Educational Institution of Higher Education "Primorskaya State Academy of Agriculture"/ FSBEI HE Primorskaya SAA 


\title{
Journal for Educators, Teachers and Trainers, Vol. 12 (1) \\ ISSN 1989 - 9572 \\ https://jett.labosfor.com/
}

\section{Bilingual education as a prospective form of tertiary education in higher education institutions}

\author{
Poddubnaya Yana Nikolaevna ${ }^{1}$, Kotov Konstantin Sergeevich ${ }^{2}$, Slukina Anastasia Alekseevna ${ }^{3}$, \\ Aleksandrova Larisa Gennadevna ${ }^{4}$, Martynova Anastasia Sergeevna ${ }^{5}$ \\ ${ }^{1,2,3,4}$ School of Education, Far Eastern Federal University, (branch) in Ussuriysk, Russia \\ ${ }^{5}$ Federal State Budgetary Educational Institution of Higher Education "Primorskaya State Academy of \\ Agriculture"/ FSBEI HE Primorskaya SAA. \\ Email ID: underoak@mail.ru, kotov.ks@mail.ru, igoruss69@mail.ru, steisha@list.ru
}

\begin{abstract}
The purpose of this study is to analyse the experience of bilingual education in higher educational institutions in Europe and consider its merits in terms of the goals of educational programs implemented in language universities.

Scientific novelty is presented in systematizing the experience of foreign teachers training students in the methodology of bilingual education; and the merits of bilingual education over common language education.

The result of the study is the creation of didactic recommendations aimed at minimizing the negative results of bilingual education, which contribute to more effective progress of students in achieving a form of bilingual thinking.
\end{abstract}

Keywords: bilingualism; bilinguals; bilingual education; language training; European bilingual programs.

\section{RELEVANCE}

The relevance of this study lies in the rapid pace of globalization, affecting all spheres of society and, in particular, the field of education. As a result of the process of creating an intercultural educational environment through the development of a single intercultural educational space, an innovative teaching methodology appeared which is called bilingual education. It has great potential in higher educational institutions.

To achieve the above set goals the following research objectives were formulated: the first is to systematize the accumulated experience of European educational programs and educational institutions teaching according to the method of bilingual education. The second task is to analyze the merits of bilingual education. The third task, which is also the practical significance of the work, is to create a list of recommendations aimed at the successful implementation of bilingual programs in higher education institutions. To solve these objectives the following theoretical research methods were used: the method of content analysis, the method of deduction, formalization, the method of generalizing the positive advanced teaching experience and the hermeneutic method.

The theoretical basis of the research were the works of Glukhikh Ya. A., Kachalova N. A. [1], Pozdnyakova A. A. [5], Khabarova L. P. [7] and Shirina A.G. [8], which consider bilingualism and bilingual education in higher education.

The main trend in the development of the modern world is the creation of a single intercultural space in which a person not only exists, but he is a creator. A person who speaks only his native language loses the opportunity to be part of a rapidly developing society.

Almost all the achievements of the last twenty years are the merit of the human language. It is the language, or namely foreign languages act as a communication bridge that helps to unite people from all over the world to achieve common goals $[7 ; 846]$. 
The main value of a foreign language lies in the fact that almost all international legal and technical documentation is presented in English, which serves as a communication tool for people all over the world.

However, now a simple knowledge of a foreign language seems to be insufficient to have an active life in the modern society. Thus, one of the main trends in education is the formation of bilingual communicative competence, which is responsible for the development of the communicative and sociocultural sphere of the individual in the whole $[1 ; 192]$.

The etymology of the word "bilingualism" has Latin roots: bi - two lingua - language [7; 846]. In other words this term implies the skill of operating in two languages. This term came into widespread usage in the 90s of the $20^{\text {th }}$ century [2].

First of all, it is necessary to distinguish between the concepts of "foreign language" and "second language". The first refers to languages that are studied regardless of the presence or absence of native speakers surrounding a student. The second language, on the contrary, is a language, the knowledge of which seems to be necessary for performing everyday actions and communicating with people around $[5 ; 25]$.

Thus, to achieve some form of bilingualism training through professionally oriented courses is not enough [7; 846]. That is why bilingual education is currently developing at an accelerated pace.

The phenomenon of bilingualism is studied by a large number of different sciences, including: linguistics, psycholinguistics, sociolinguistics and others. Such a wide range of sciences studying bilingualism is due to the fact that there are many classifications of bilingualism, which include various components: social, cognitive, developmental and linguistic [7; 846].

For instance, S.S. Sorokina highlighted the following typology of bilingualism in her article:

1. From the point of view of the educational and methodological component: unorganized and organized type of bilingualism.

2. From the point of view of sociology:

a) artificial and natural type of bilingualism. This type depends on the social conditions in which a person is located;

b) individual, group and mass - depending on the degree of distribution.

3. In terms of the psychological component:

a) complete and incomplete bilingualism, divided according to the degree of assimilation of bilingual mechanisms;

b) productive, perceptual and receptive types - according to the degree of language proficiency;

c) pure and mixed type of bilingualism is characterized by the degree of rooting of bilingual mechanisms in the human mind.

4. From the point of view of the linguistic component, bilingualism is divided into subordinate and coordinate expressed in the degree of observance of the linguistic norms of both languages [5;26].

This typology of bilingualism is the main criterion for the correct choice of teaching methods on a bilingual basis implemented in higher educational institutions [5; 27].

The authors of the article consider it especially important to emphasize that bilingual education differs greatly from the language organization of education.

Thus, Baker believes that education on a bilingual basis is education in which students actively work with lesson material in more than one language [7; 847].

This method of education seems to be especially relevant for educational institutions specializing in teaching a foreign language. This trend is based on the fact that a foreign language is used as a teaching tool which helps students to immerse themselves as much as possible in the intercultural language environment [5; 27].

However, it should be noted that the goals and techniques of bilingual education have significant differences from the ones of language teaching used in higher education institutions.

The main differences between bilingual and language teaching are the following:

1. The goal of bilingual education is to achieve a form of bilingualism, while language teaching is aimed to the process of mastering a foreign language.

2. The main academic goal of bilingual education is to teach students, using two languages at the same time, to work with different cultures, whereas the academic goal of language education is to master a foreign language.

3. In teaching on a bilingual basis a foreign language is used as a means of teaching, and in a language one it is used as a subject of teaching. 
4. The usage of two or more languages in teaching is inherent in bilingual education.

5. The pedagogical value of bilingual education is the integration of the target language into the content of education, while the importance of language education is the study of the language $[7 ; 848]$.

However, sometimes bilingual educational programs have some similarities with langyage ones. For example, the language training program IntegralLearning, aimed directly at learning of a foreign language, increasingly integrates the language into the content of training, which to some extent makes this program related to the training based on bilingual education. On the contrary, some bilingual programs are based on the principles of language teaching, which include: no translation and no use of several languages in one lesson [6; 848].

Despite some similarities of these programs, the different goals implemented in the learning process do not allow us to consider them as integral components of language learning, which allows us to conclude that bilingual programs are qualitatively different from language ones.

The goal of bilingual education is not limited to mastering a foreign language. The main goal pursued by teachers is to educate a responsible citizen who is able to work with cultures which differ from the native one, and think globally going beyond the cultural framework [7; 848].

Bilingual education is also divided according to the degree of use of the native language in the educational process. So, there are 5 types of bilingual education:

1. Submersion. This type of training involves presence of a student in a foreign language class regardless of the level of his knowledge. The essence of this type is that a student is to study the subjects of the general course simultaneously with the acquisition of a foreign language.

2. Bilateral bilingual education. The group of students consists of native speakers of two different languages. Classes are held alternately in both languages for several years.

3. Foreign language as a second language. This type has many similarities with submersion, except that a student spends some part of the training time with a foreign language teacher, during which he studies the language profoundly. A distinctive feature of this method is that a student is examined in subjects that are taught to him in a foreign language, and it increases his motivation to master a foreign language as soon as possible.

4. The immersion type of bilingual education implies that foreign students, who represent the majority of the training group, are taught entirely in a foreign language. Immersion, in turn, is divided into partial, when half of the academic disciplines are taught in a language which is not a native one, and complete, when all the subjects are taught in a foreign language.

5. Trilingual system of bilingual education. With this form of education, the native language is supplanted by the introduction of new foreign languages, which gradually partially replace each other. It is assumed that at the end of the course, a student will be fluent in three languages: a native and two foreign ones [7; 850].

Many researchers, including D. Atkinson, E.G. Voltaire, L. Prodromou and others note that the native language can help students to master a foreign language if it is used systematically, which meets the main goal of bilingual education - mastering some form of bilingualism [1; 192].

Models of bilingual education are also divided into: supportive, transitional and enriching.

1. The main principle of the supportive model is to encourage bilingualism and biculturalism.

2. Transitional, also known as monolinguism, allows you to transfer a student from their native language completely to a foreign one. With this program, the main goal is to master a foreign language as soon as possible.

3. Enrichment program. A model aimed at promoting the acquisition of a foreign language, regardless of the goal of achieving full bilingualism or mastering a foreign language competence required to perform a specific job [7; 850], [10].

It should be clarified that the advantages of bilingual education, first of all, were appreciated at their true worth in higher educational institutions in Europe. Currently, a wide range of educational programs based on bilingual education have been created in the European Union:

1. Socrates. This program is one of the broadest according to the degree of covered countries by it and it has 31 participating countries. The main goal of the educational program is to develop cooperation among the countries of the European Union to improve the quality of education.

2. ErasmusMundus. A program aimed at providing graduates of various foreign universities with the opportunity to get further education. 
3. LeonardodaVinci is a program that develops professional training through the exchange students from various universities with friendly companies and organizations located in different European countries.

4. Tempus. The program of trans-European mobility in the field of higher education, which is also implemented in partner countries, among which is Russia.

5. "Academic year in Spain, France or Germany". A program that supports the study of Spanish, French and German through study at higher education institutions in these countries [5;27].

Higher educational institutions of Russia, based on the experience of European countries, set the primary task to integrate and develop bilingual education in their country. Thus, the "Novgorod", "Saratov", "St. Petersburg" and "Perm" concepts of bilingual education were created $[7 ; 850]$.

Thus, with the great positive influence of telecommunication technologies on the education, the development of bilingual education is increasingly becoming a global trend. Many scholars belonging to various fields of scientific activity (psychology, psycholinguistics, linguistics and political science) also speak of bilingual education as the main vector of the development of the higher education system in the $21^{\text {st }}$ century [5; 27].

This trend is due to the high efficiency and the absence of negative factors of bilingual education. This is evidenced by researches of Otto von Guericke University and the University of Wales, which found that bilingual education is more successful than the widespread language teaching [6;94].

A German teacher Endt detailed the results of a comparative research of a group of students who are taught on the principle of bilingual education:

- it is noted that the level of oral speech proficiency was much higher than the knowledge of grammar in the first year of study, but after a while the students reached the level of control groups;

- the rapid pace of development of listening and reading skills is especially highlighted;

- knowledge of basic subjects remained at a high level;

- advanced development of cognitive ability;

- high intellectual potential of students $[9 ; 5]$.

Thus, the researchers first of all highlight that the introduction of subjects taught in a foreign language has a positive effect on the communicative competence of students, as a result of which students do not experience discomfort when communicating with native speakers of a foreign language. In common identical conditions bilingual-based classes are ahead of their peers in learning a foreign language by an average of 2 academic years $[6 ; 94]$

The results of numerous researches conducted over the past decades also indicate that bilingual education has a fruitful effect on the overall mental development of a child, expressed in improving memory, logic and bilingual thinking [7; 850].

Social and social psychic new formations also include high tolerance and mobility of students, expressed in the fact that students are able to understand not only their native culture and they integrate into a foreign culture and community successfully [2].

However, some scholars are sure that lagging students find it difficult to cope with the additional work inherent in a bilingual curriculum. This negatively affected their educational performance $[4 ; 68]$.

Critics also say that teaching basic subjects in a foreign language reduces the amount of acquired knowledge, which contradicts the conclusion of DESI-Studie, published in 2008, which reported that bilingual education is extremely successful and the deterioration of the native language was not noticed [6;94].

However, the authors of the article agree with the opinion of I. A. Zimnyaya about the fact that it is necessary to conduct lessons on a bilingual basis since this innovative teaching methodology, in spite of a small number of shortcomings, shows very high results $[1 ; 194]$.

Thus, having analyzed the experience of implementing bilingual education in higher educational institutions of different countries, the authors of the article consider it possible to systematize the accumulated experience of the teachers, and offer the following recommendations, which will further contribute to minimizing negative aspects when introducing bilingual education into the educational field of language universities:

1. When choosing a foreign language in which the subjects of the general course will be taught, it is necessary to pay attention to the following theses:

a) conducting classes in a genealogically related language has a positive effect on the process of mastering a foreign language; 
b) the possibility of conducting classes taking into account the comparative-contrast aspect, which contributes to the developing of thinking in a foreign language;

c) training should be structured so that speech patterns and lesson topics used in the native language can be easily integrated into the foreign language [4; 759].

2. When implementing training on the basis of bilingual education, it is necessary:

a) to conduct the entire course on a bilingual basis, without stopping the implementation of the program;

b) subjects of the general course, which are of the main importance for a particular training program, should be duplicated in the students' native language during additional lessons, which will ensure a complete understanding of the material;

c) teachers must have sufficient competence both in the subject they teach and in the linguistic aspect;

d) to reduce the number of group forms of work, but at the same time not to exclude them from the educational process. [7; 850], [6; 95].

3. Also, when choosing the content of the course, it is necessary to take into account the specifics of bilingual education:

a) the principle of two-sided assessment, expressed in the possibility of perceiving information from the point of view of the cultures of the countries whose language is being studied;

b) the principle of reflection on trends in global integration;

c) the principle of the comparative-analytical presentation of the material of the classes, expressed in affecting the culture, state and society of the country of the studied language $[8 ; 63],[4 ; 755]$.

4. Control, implemented in bilingual education, first of all, should check the knowledge of students in the aspect of subject-communicative actions, that is, the quality of knowledge with simultaneous teaching in two languages.

The following assessment criteria are recommended:

a) the result of solving communicative-subject tasks;

b) the creative nature of cognitive activity;

c) the quality of knowledge of basic subjects;

d) the quality of communication;

e) the degree of possibility of solving problems independently [1; 194].

It should also be noted that in bilingual education it is necessary to limit the use of the native language to a minimum. A foreign language, in its turn, should be the main tool for presenting information [8; 65].

I. G. Vladimirova identifies the following situations in which the use of the native language in bilingual education is considered justified:

1. When studying vocabulary.

2. When implementing comparative analysis.

3. To relieve the emotional stress of students, provoked by insufficient language competence of students when solving an educational problem $[8 ; 65]$.

The authors of the article believe that using these recommendations will help eliminate negative consequences and increase the effectiveness of bilingual education.

Thus, the authors of the article suppose that the use of bilingual education in higher educational institutions is fully justified. First of all, the effectiveness is expressed in the fact that the principles of the bilingual approach in the process of teaching perfectly correlate with the main goals of the higher education system, namely: the development of the student's creative personality and the expansion of their opportunities for obtaining a qualitative education $[4 ; 759]$.

Bilingual education has its own specifics, therefore, having a wide range of didactic tools and using the experience of foreign and domestic bilingual schools, high-quality prerequisites are created for the upbringing of bilinguals that meet modern personality requirements through the introduction of high-quality bilingual educational programs in higher educational institutions.

\section{REFERENCES}

1. Gluhih Ja.A., Kachalov N.A. Bilingual training in the conditions of modernization of modern education // Bulletin of Tomsk State Pedagogical University. 2013. Vol. 135. Issue No. 7. 
2. Infourok: electronic library system. - URL: https://infourok.ru/statya-bilingvalnoe-obuchenie-itendencii-ego-razvitiya-1726723.html (date of access: 13.12.2020).

3. Moskovskaja L.N. Bilingvalny education at a higher school: problems and solutions // Izvestia Penza State Pedagogical University named after V.G. Belinsky. - 2011.

4. Mosin M.V., Vodjasova L.P., Mosina N.M., Chinaeva N.V. Bilingualism's didactic potential in teaching a foreign language // Integration of education. 2017. Vol. 21. Issue No. 4.

5. Pozdnjakova A.A. Bilinguism and bilingual education // Science and school. 2012. Issue No. 4.

6. Razumova N.V Bilingual education in Germany // Science without borders. 2018. Vol. 27. Issue No. 10.

7. Habarova L.P. Bilingual education at a higher school: foreign and domestic experience // News of the Penza State Pedagogical University named after V.G. Belinsky. 2011. Issue No. 24.

8. Shirin A.G. Didactic-methodical aspects of the process of bilingual education // Bulletin of Novgorod State University. 2005. Issue No. 31.

9. DailyEducator: electronic library system. - URL: http://www.dailyeducator.ru/moseks-3261.html (date of access 14.12.2020).

10. Studbooks: electronic library system. - URL: https://studbooks.net/2044734/pedagogika/bilingvalnoe_obuchenie_innovatsionnyh_metodov _obucheniya (date of access 13.12.2020). 